\title{
GAMBARAN PENGETAHUAN IBU HAMIL TRIMESTER III TENTANG \\ TANDA-TANDA BAHAYA KEHAMILAN BERDASARKAN \\ USIA, PENDIDIKAN DAN PEKERJAAN \\ DI BPS SULASTINI A.Md.Keb
}

\author{
Fitriana Ikhtiarinawati Fajrin* \\ *Dosen Program Studi DIII Kebidanan Universitas Islam Lamongan \\ Email: fitrianaikhtiarinawatifajrin@gmail.com
}

Penelitian ini bertujuan untuk: 1) Mengidentifikasi pengetahuan ibu hamil Trimester III tentang tanda-tanda bahaya kehamilan berdasarkan usia. 2) Mengidentifikasi pengetahuan ibu hamil Trimester III tentang tanda-tanda bahaya kehamilan berdasarkan pendidikan. 3) Mengidentifikasi pengetahuan ibu hamil Trimester III tentang tanda-tanda bahaya kehamilan berdasarkan pekerjaan.

Penelitian ini menggunakan rancangan penelitian Deksriptif Cross Sectional. Populasi dalam penelitian ini adalah seluruh ibu hamil trimester III yang memeriksakan kehamilannya pada bulan Maret - Mei 2017di BPS Sulastini A.Md.Keb. Desa Masaran, Kecamatan Banyuates, Kabupaten Sampang. Sampel dalam penelitian ini adalah semua populasi dijadikan sebagai sampel. Instrumen yang digunakan dalam penelitian ini adalah kuesioner.

Hasil penelitian ini menunjukkan:1). Pengetahuan ibu hamil trimester III tentang tanda-tanda bahaya kehamilan berdasarkan usia, sebagian besar usia reproduksi sehat (20-35 tahun) memiliki pengetahuan baik. 2). Pengetahuan ibu hamil trimester III tentang tandatanda bahaya kehamilan berdasarkan pendidikan, sebagaian besar pendidikan menengahpengetahuan baik. 3). Pengetahuan ibu hamil trimester III tentang tanda-tanda bahaya kehamilan berdasarkan pekerjaan, sebagian besar responden yang bekerjadengan pengetahuan baik. Simpulan dari penelitian ini adalah usia, pendidikan dan pekerjaan ibu berpengaruh terhadap pengetahuan ibu hamil tentang tanda-tanda bahaya kehamilan TM III.

\section{Keyword: Tanda-tanda bahaya kehamilan, Usia, Pendidikan, Pekerjaan.}

\section{PENDAHULUAN}

Kehamilan adalah masa dimulai dari konsepsi sampai lahirnya janin, kehamilan berlangsung selama 280 hari (40 minggu atau 9 bulan 7 hari) di hitung dari hari pertama haid terakhir (HPHT) (Altahira, 2014). Suatu kehamilan selalu mempunyai resiko dengan kemungkinan bahaya atau resiko terjadinya komplikasi dapat ringan atau berat yang menyebabkan terjadinya kematian, kesakitan, kecacatan, pada ibu atau bayi (Rochijati, 2003).

$$
\text { Menurut Direktorat Bina }
$$

Kesehatan Keluarga bekerjasama dengan Pusat Penyuluhan Kesehatan Masarakat Depkes dan Kesos, Tim Penggerak PKK Pusat dan Kantor Perwakilan WHO di Jakarta, tanda bahaya kehamilan adalah gejala yang menunjukkan ibu dan bayi dalam keadaan bahaya. 15-20 diantara 100 ibu hamil mengalami gangguan pada kehamilan. Gangguan tersebut dapat terjadi secara mendadak dan biasanya tidak dapat diperkirakan sebelumnya, karena itusetiap ibu hamil, keluarga dan masyarakat perlu mengetahui dan mengenali tanda-tanda bahaya dan gejala yang menunjukkan bahwa ibu dan bayi dalam keadaan bahaya.

Tanda bahaya pada masa kehamilan perlu diketahui oleh klien terutama yang mengancam keselamatan ibu maupun janin yang dikandungnya sesuai dengan program di pemerintah, minimal yang perlu diketahui masyarakat untuk mengenal tanda bahaya kehamilan yaitu perdarahan, gerakan janin berkurang, bengkak pada muka dan tangan, nyeri 
perut, masalah penglihatan, dan sakit kepala yang hebat (Salmah, 2006).

Perawatan selama kehamilan yang baik, dapat mengurangi kematian maternal dan perinatal. Perbaikan aspek sosial, budaya, ekonomi dan pendidikan, dapat membantu mengatasi $64 \%$ penyebab kematian ibu. Perbaikan penanganan klinis, dapat mengatasi 36\% kematian ibu. Kesadaran masyarakat akan tanda-tanda bahaya pada kehamilan akan meminimalkan kegawatdaruratan obstetric sebesar $48 \%$, dan pengetahuan mengenal kehamilan akan meminimalkan kegawatdaruratan obstetric sebesar $52 \%$. Solusi dari masalah tersebut di atas yaitu setiap ibu hamil perlu diberikan penyuluhan tentang tanda-tanda bahaya dalam kehamilan, dan meminta ibu agar segera meminta pertolongan pada tenaga kesehatan apabila mengalami salah satu atau lebih dari tanda bahaya kehamilan tersebut.

Dalam studi pendahuluan yang dilakukan di BPS Sulastini, Amd.Keb dari 10 orang ibu hamil trimester III, yang pengetahuannya baik tentang tanda-tanda bahaya kehamilan 4 orang (40\%), yang pengetahuannya cukup ada 3 orang $(30 \%)$, dan yang pengetahuannya kurang sejumlah 3 orang (30\%). Dari hasil studi pendahuluan dapatdisimpulkan bahwaibu hamil yang memiliki pengetahuan ibu baik tentang tanda-tanda bahaya kehamilan hanya berjumlah $40 \%$, seharusnya seluruh ibu hamil memiliki pengetahuan yang baik mengenenai tanda-tanda bahaya kehamilan. Dari uraian di atassehingga peneliti tertarik untuk melakukan penelitian mengenai gambaran tingkat pengetahuan ibu hamil trimester III tentang tanda-tanda bahaya kehamilan di BPS Sulastini, Amd.Keb, Desa Masaran Kec. Banyuates.

\section{METODE PENELITIAN}

Penelitian ini menggunakan rancangan penelitian Deksriptif Cross Sectional. Populasi dalam penelitian ini adalah seluruh ibu hamil trimester III yang memeriksakan kehamilannya pada bulan Maret - Mei 2017 di BPS Sulastini A.Md.Keb. Desa Masaran Kecamatan Banyuates, Kabupaten Sampang. Sampel dalam penelitian ini adalah semua populasi dijadikan sebagai sampel. Instrumen yang digunakan dalam penelitian ini adalah kuesioner. Dari data yang terkumpul, kemudian data dianalisa dengan menggunakan tabel distribusi dan tabel frekuensi yang dikonfirmasikan dalam bentuk persentase dan narasi kemudian dilakukan tabulasi silang tanpa uji statistik.

\section{HASIL PENELITIAN}

\section{Data Pengetahuan Ibu Tentang}

\section{Tanda-Tanda Bahaya KehamilanTM}

\section{Berdasarkan Usia}

Tabel 4.1Distribusi Pengetahuan Ibu Hamil Trimester III Tentang TandaTanda Kehamilan Berdasarkan Usia di BPS Sulastini, Amd.Keb. Desa Masaran Kecamatan Banyuates Kabupaten Sampangtanggal 01 Maret - 30 Mei 2017

\begin{tabular}{|c|c|c|c|c|c|c|c|c|}
\hline \multirow{3}{*}{$\begin{array}{c}\text { Pengetahuan } \\
\text { Ibu Hamil } \\
\text { Trimester III } \\
\text { Tentang } \\
\text { Tanda- } \\
\text { Tanda } \\
\text { Kehamilan } \\
\end{array}$} & \multicolumn{6}{|c|}{ Usia } & \multirow{2}{*}{\multicolumn{2}{|c|}{ Jumlah }} \\
\hline & \multicolumn{2}{|c|}{$\begin{array}{l}<20 \\
\text { tahun }\end{array}$} & \multicolumn{2}{|c|}{$\begin{array}{c}20-35 \\
\text { tahun }\end{array}$} & \multicolumn{2}{|c|}{$>35$ tahun } & & \\
\hline & $\mathrm{N}$ & $\%$ & $\mathrm{~N}$ & $\%$ & $\mathrm{~N}$ & $\%$ & $\mathrm{~N}$ & $\%$ \\
\hline Baik & 3 & 10 & 8 & 27 & 4 & 13 & 15 & 50 \\
\hline Sedang & 4 & 13 & 5 & 17 & 1 & 3 & 10 & 33 \\
\hline Kurang & 1 & 3 & 3 & 10 & 1 & 3 & 5 & 17 \\
\hline Jumlah & 8 & 26 & 16 & 54 & 6 & 19 & 30 & 100 \\
\hline
\end{tabular}

Dari tabel 4.1 dapat dilihat bahwa dari 30ibu hamil mayoritas berusia 2035 tahun sejumlah 16 orang (54\%) dan ibu hamil usia 20-35 tahun tersebut mayoritas memiliki pengetahuan baik tentang tanda-tanda bahaya kehamilan TM III sebanyak 8 orang (27 \%), sedangkan untuk pengetahuan sedang sebanyak 5 orang $(17 \%)$ dan pengetahuan kurang sebanyak 3 orang $(10 \%)$. 


\section{Data Pengetahuan Ibu Tentang}

Tanda-Tanda Bahaya KehamilanTM

\section{Berdasarkan Pendidikan}

Tabel 4.2Distribusi Pengetahuan Ibu Hamil Trimester III Tentang TandaTanda Kehamilan Berdasarkan Pendidikan di BPS Sulastini, Amd.Keb. Desa Masaran Kecamatan Banyuates Kabupaten Sampangtanggal 01 Maret 30 Mei 2017

\begin{tabular}{|c|c|c|c|c|c|c|c|c|}
\hline \multirow{3}{*}{$\begin{array}{c}\text { Pengetahuan } \\
\text { Ibu Hamil } \\
\text { Trimester III } \\
\text { Tentang } \\
\text { Tanda- } \\
\text { Tanda } \\
\text { Kehamilan }\end{array}$} & \multicolumn{6}{|c|}{ Pendidikan } & \multirow{2}{*}{\multicolumn{2}{|c|}{ Jumlah }} \\
\hline & \multicolumn{2}{|c|}{$\begin{array}{l}\text { SD/ SMP } \\
\text { (Pendidikan } \\
\text { Dasar) }\end{array}$} & \multicolumn{2}{|c|}{$\begin{array}{c}\text { SMA } \\
\text { (Pendidikan } \\
\text { Menengah) }\end{array}$} & \multicolumn{2}{|c|}{$\begin{array}{c}\text { Perguruan } \\
\text { Tinggi } \\
\text { (Pendidikan } \\
\text { Tinggi) } \\
\end{array}$} & & \\
\hline & $\mathrm{N}$ & $\%$ & $\mathrm{~N}$ & $\%$ & $\mathrm{~N}$ & $\%$ & $\mathrm{~N}$ & $\%$ \\
\hline Baik & 3 & 10 & 9 & 33,3 & 2 & 6,7 & 15 & 50 \\
\hline Sedang & 3 & 10 & 4 & 13,3 & 2 & 6,7 & 10 & 33 \\
\hline Kurang & 2 & 6,7 & 3 & 10 & 1 & 3,3 & 5 & 17 \\
\hline Jumlah & 8 & 26,7 & 17 & 56,6 & 5 & 16,7 & 30 & 100 \\
\hline
\end{tabular}

Dari tabel 4.2 dapat dilihat bahwa dari 30ibu hamil mayoritas berpendidikan menengah sejumlah 17 orang $(56,6 \%)$ dan ibu hamil berpendidikan menengah tersebut mayoritas memiliki pengetahuan baik tentang tanda-tanda bahaya kehamilan TM III sebanyak 10 orang (33,3 \%), sedangkan untuk pengetahuan sedang sebanyak 4 orang $(13,3 \%)$ dan pengetahuan kurang sebanyak 3 orang $(10 \%)$.

\section{Data Pengetahuan Ibu Tentang}

\section{Tanda-Tanda Bahaya KehamilanTM}

\section{Berdasarkan Pekerjaan}

Tabel 4.3Distribusi Pengetahuan Ibu Hamil Trimester III Tentang TandaTanda Kehamilan Berdasarkan Pekerjaan di BPS Sulastini, Amd.Keb. Desa Masaran Kecamatan Banyuates Kabupaten Sampangtanggal 01 Maret 30 Mei 2017

\begin{tabular}{|c|c|c|c|c|c|c|}
\hline \multirow{3}{*}{$\begin{array}{l}\text { Pengetahuan } \\
\text { Ibu Hamil } \\
\text { Trimester III } \\
\text { Tentang } \\
\text { Tanda-Tanda } \\
\text { Kehamilan }\end{array}$} & \multicolumn{4}{|c|}{ Pekerjaan } & \multicolumn{2}{|c|}{ Jumlah } \\
\hline & \multicolumn{2}{|c|}{$\begin{array}{c}\text { Tidak } \\
\text { Bekerja }\end{array}$} & \multicolumn{2}{|c|}{ Bekerja } & & \\
\hline & $\mathrm{N}$ & $\%$ & $\mathrm{~N}$ & $\%$ & $\mathrm{~N}$ & $\%$ \\
\hline Baik & 5 & 17 & 10 & 33 & 15 & 50 \\
\hline Sedang & 7 & 24 & 3 & 10 & 10 & 33 \\
\hline Kurang & 1 & 3 & 4 & 13 & 5 & 17 \\
\hline Jumlah & 13 & 44 & 17 & 56 & 30 & 100 \\
\hline
\end{tabular}

Sumber: Data Primer, 2017

Dari tabel 4.3 dapat dilihat bahwa dari 30ibu hamil mayoritas bekerja sejumlah 17 orang $(56 \%)$ dan ibu hamil bekerja tersebut mayoritas memiliki pengetahuan baik tentang tanda-tanda bahaya kehamilan TM III sebanyak 10 orang (33\%), sedangkan untuk pengetahuan sedang sebanyak 3 orang $(10 \%)$ dan pengetahuan kurang sebanyak 4 orang $(13 \%)$.

\section{PEMBAHASAN}

\section{Pengetahuan Ibu Tentang Tanda-}

Tanda Bahaya KehamilanTM III

\section{Berdasarkan Usia}

Dari tabel 4.1 dapat dilihat bahwa dari 30ibu hamil mayoritas berusia 2035 tahun sejumlah 16 orang $(54 \%)$ dan ibu hamil usia 20-35 tahun tersebut mayoritas memiliki pengetahuan baik tentang tanda-tanda bahaya kehamilan TM III sebanyak 8 orang (27 \%), sedangkan untuk pengetahuan sedang sebanyak 5 orang (17\%) dan pengetahuan kurang sebanyak 3 orang $(10 \%)$.

Usia adalah umur individu yang terhitung mulai saat dilahirkan sampai saatberulang tahun.Semakin cukup usia, tingkat kematangan atau kemampuan seseorang akan lebih matang dalam berfikir dan menerima informasi (Burlock: 1998 yang dikutip pariani :2001). Hasil penelitian ini sesuai denganpendapat Notoatmodjo (2006), semakin bertambah umur seseorang maka semakinmatang berfikir dan 
semakin banyak pengalamannya tentang kesehatan. Semakinbertambah umur seseorang semakin tinggi pengetahuannya. Ibu hamil yang berada pada umur 20-35 tahun memiliki pengetahun yang baik tentang tanda bahaya kehamilandan lebih mudah menerima informasi yang diperoleh sehingga lebih cepatmengerti dan mudah memahami apa yang telah disampaikan bidan atau petugas kesehatan selain itu, ibu hamil yang mayoritas usia 20-35 tahun atau di sebut usia produktif memiliki pengetahuan yang baik karena pengetahuan seseorang dapat diperoleh dari beberapa hal. Pengetahuan merupakan hasil "tahu" dan terjadi setelah orang melakukan penginderaan terhadap suatu obyek tertentu. Penginderaan terjadi melalui panca indera manusia yakni indera penglihatan, pendengaran, penciuman, rasa, dan raba. Sebagian besar pengetahuan manusia diperoleh melalui mata dan telinga. Pengetahuan merupakan domain yang sangat penting untuk terbentuknya tindakan seseorang/over behavior (Notoadmodjo, 2003). Hal ini dapat di artikan bahwa semakin tua usia seorang akan semakin banyak pengetahuan karena pengetahuan seseorang dapat diperoleh dari pengalaman diri sebelumnya atau pengalaman dari orang lain, dari beberapa pengalaman tersebut akan memperbanyak pengetahuan ibu khususnya tentang tanda-tanda bahaya kehamilan.

\section{Pengetahuan Ibu Tentang Tanda-}

\section{Tanda Bahaya KehamilanTM III}

\section{Berdasarkan Pendidikan}

Pada tabel 4.2 menunjukkan bahwa dari 30ibu hamil mayoritas berpendidikan menengah sejumlah 17 orang $(56,6 \%)$ dan ibu hamil berpendidikan menengah tersebut mayoritas memiliki pengetahuan baik tentang tanda-tanda bahaya kehamilan TM III sebanyak 10 orang $(33,3 \%)$, sedangkan untuk pengetahuan sedang sebanyak 4 orang $(13,3 \%)$ dan pengetahuan kurang sebanyak 3 orang (10\%).

Data di atas sejalan dengan teori yang ada bahwa pendidikan adalah suatu usaha untuk mengembangkan kepribadian kemampuan di dalam dan di luar sekolah, dan berlangsung seumur hidup (Notoadmodjo, 2003), menurut Kuncoroningrat (1997) dikutip oleh Nursalam dan Pariani (2001), makin tinggi pendidikan seseorang makin mudah orang tersebut menerima informasi, baik dari orang lain maupun dari media massa, semakin banyak informasi yang masuk semakin banyak pula pengetahuan yang didapat tentang kesehatan.Jenjang pendidikan adalah tahapan yang diterapkan berdasarkan tingkat perkembangan peserta didik, tujuan yang akan dicapai dari kemampuan yang dikembangkan (Depdiknas, 2003).Selain itu peningkatan pengetahuan tidak mutlak diperoleh dari pendidikan formal, akan tetapi dapat diperoleh pada pendidikan non formal. Pengetahuan seseorang tentang suatu subjek mengandung dua aspek yaitu aspek positif dan negatif. Kedua aspek inilah yang akhirnya akan menentukan sikap seseorang tehadap objek tertentu. Semakin banyak aspek positif dari objek yang diketahuai, akan menumbuhkan sikap makin positif terhadap objek tersebut (Pro-Health, 2009). Dalam hal ini pendidikan non formal dapat diperoleh dari petugas kesehatan dalam memberikan informasi, sehingga dapat membantu ibu hamiluntuk memperoleh pengetahuan tentang tanda-tanda bahaya kehamilan.

Meskipun demikian berdasarkan data diatas ibu hamil dengan pendidikan menengah beberapa diantaranya memiliki pengetahuan tentang tandatanda bahaya kehamilan TM III sedang 
atau bahkan kurang, hal ini bermakna bahwa ibu yang berpendidikan menengah tidak berarti mutlak secara keseluruhanberpengetahuan baik di karenakan daya tangkap dan kemampuan seseorang dalam menerima informasi berbeda-beda.

\section{Pengetahuan Ibu Tentang Tanda-} Tanda Bahaya KehamilanTM III

\section{Berdasarkan pekerjaan}

Dari tabel 4.3 dapat dilihat bahwa dari 30ibu hamil mayoritas bekerja sejumlah 17 orang $(56 \%)$ dan ibu hamil bekerja tersebut mayoritas memiliki pengetahuan baik tentang tanda-tanda bahaya kehamilan TM III sebanyak 10 orang (33\%), sedangkan untuk pengetahuan sedang sebanyak 3 orang (10 \%) dan pengetahuan kurang sebanyak 4 orang $(13 \%)$.

Menurut Sukmadinata (2003) manusia adalah makhluk sosial, dimana dalam kehidupan individu satu saling berinteraksi dengan individu yang lain sehingga terpapar informasi. Melalui pekerjaan dan rutinitas seseorang akan berinteraksi dengan orang lain dan dapat memperoleh informasi. Informasi yang di peroleh dari berbagai sumber akan mempengaruhi tingkat pengetahuan seseorang, jika seseorang memperoleh banyak informasi maka akan cenderung mempunyai pengetahuan yang lebih luas. Data hasil penelitian sesuai dengan teori yang ada, bahwa ibu yang bekerja memiliki pengetahuan baik mengenai tanda-tanda bahaya kehamilan. Hal ini dapat terjadi karena ibu yang bekerja sering berinteraksi dengan individu yang lain sehingga dapat bertukar informasi/ pengalaman hidup dari kehamilan yang pernah di alami sebelumnya sehinggamenyebabkanibu hamil TM III yang bekerja mayoritas memiliki pengetahuan baik mengenai tanda-tanda bahaya kehamilan.

\section{KESIMPULAN DAN SARAN}

\section{Simpulan}

1. Pengetahuan ibu hamil trimester III tentang tanda-tanda bahaya kehamilan berdasarkan usia, sebagian besar usia reproduksi sehat (20-35 tahun) memiliki pengetahuan baik.

2. Pengetahuan ibu hamil trimester III tentang tanda-tanda bahaya kehamilan berdasarkan pendidikan, sebagaian besar pendidikan menengah dan memiliki pengetahuan baik.

3. Pengetahuan ibu hamil trimester III tentang tanda-tanda bahaya kehamilan berdasarkan pekerjaan, sebagian besar responden bekerja denganpengetahuan baik.

\section{Saran}

1. Hasil penelitian ini dapat dijadikan bahan dalam memberikan komunikasi, informasi. edukasi (KIE) kepada ibu hamil tentang tanda-tanda bahaya kehamilan.

2. Dapat dilakukan penyuluhan tentang tanda-tanda bahaya kehamilan kepada seluruh ibu hamil agar ibu hamil dapat mengetahui serta mendeteksi secara dini komplikasi/ bahaya dalam kehamilan

3. Bagi peneliti selanjutnya, perlu dilakukan penelitian lebih lanjut tentang faktor-faktorlain yang dapat mempengaruhi pengetahuan ibu hamil tentang tanda-tanda bahaya kehamilan.

\section{DAFTAR PUSTAKA}

Altahira, Sutrisna. 2014. Asuhan Kebidanan (kehamilan). Bau bau: akbidykin

Depdiknas, 2003. Undang-undang Republik Indonesia Nomor 21 Tahun 2003 tentang Sistem Pendidikan Nasional. Pusdiknakes. Jakarta.

Nursalam, P. 2001. Pendekatan Praktis Manusia Metodelogi Riset Keperawatan. Jakarta : Sugeng Seto 
Notoatmodjo, S.2003. Pendidikan dan

Perilaku Kesehatan. Jakarta:

Rineka Cipta.

- 2007. Pendidikan Dan Perilaku

Kesehatan. Jakarta: Rineka Cipta.

Rochyati, Poedji. 2003. Skrining Antenatal pada ibu Hamil. Airangga University Press: Surabaya

Salmah. 2006. Asuhan Antenatal. Jakarta : EGC

Sukmadinata, N. (2003). Landasan Psikologi Proses pendidikan. Bandung: PT Remaja Pusdakarya.

Pro-Health. 2009. Faktor- faktor yang mempengaruhi pengetahuan. Dalam http:// forbetterhalth.Wordpress.com. 